\title{
Spectrum of Complications of Patients with Chronic Kidney Disease on Maintenance Continuous Ambulatory Peritoneal Dialysis: An Experience of Tertiary Nephrology Center in Najaf City-Iraq
}

\author{
Evan Noori ${ }^{1}$, Rawaa Hadi $^{2 *}$ (D) Yasir Sharba $^{3}$ (D) Zahraa Fathi Sharba $^{2}$ (D) \\ ${ }^{1}$ Department of Clinical Pharmacy, College of Pharmacy, University of Kufa, Kufa, Iraq; ${ }^{2}$ Department of Pharmacology and \\ Toxicology, College of Pharmacy, University of Kufa, Kufa, Iraq; ${ }^{3}$ Najaf Nephrology and Transplant Center, Kufa, Iraq
}

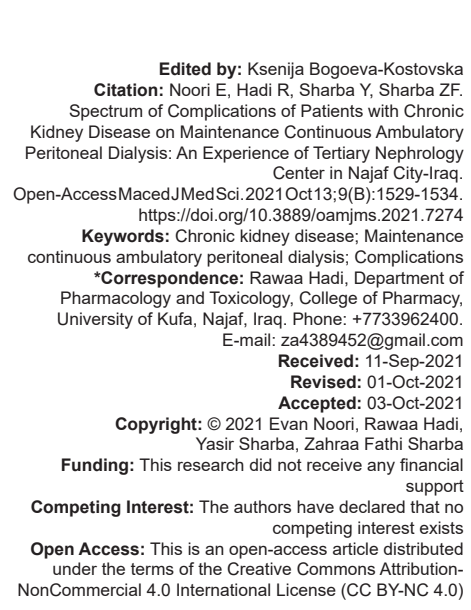

\section{Introduction}

Chronic kidney disease (CKD) is a destructive disorder with increasing global burden affecting about $10-13 \%$ of populations with over 750 million persons worldwide [1], [2], [3]. It reaching the epidemic levels due to increase the prevalence of its fundamental causes such as diabetes mellitus, hypertension, obesity, and aging process [4]. The global estimated prevalence of this disease is about $13.4 \%$ that doubled over the past three decades [5], [6], [7]. It is considered as a leading public health problems including morbidity and mortality, where CKD is considered as the $5^{\text {th }}$ growing leading cause of mortality in the world, resulted in 1.2 and 2.4 million deaths in 2019 and 2020, respectively [8], [9], [10].

In Iraq, CKD is ranked among the five most life-threatening disease, where death because of renal failure was about 6879 patients in 2015 according to the statistics of Iraqi Ministry of Health. Females patients had slightly higher mortality rates $(6.9 / 3163)$ than male (6.1/3716) [11].
The estimation of patients with end-stage kidney disease who need renal replacement therapy (RRT) is between 4.902 and 7.083 million as a result there is a growing need for cost-effective RRT [1], [5].

Peritoneal dialysis (PD) is a method of RRT and it is done by injecting the dialysis fluid that also known as dialysate into the peritoneal cavity by entering a catheter into the anterior abdominal wall and piercing the parietal peritoneum with its tip positioned in the pelvis. The peritoneum and its fenestrated capillary bed are responsible for the exchange of many substances such as electrolytes, glucose, urea, and other small molecules from the blood because it is acting as a semipermeable membrane. The solute is removed from the peritoneal capillaries by a diffusion process and through chemical gradient into the dialysate, while the removal of water done by creation of osmotic gradient by hypertonic dextrose [12], [13].

PD can be done automatically with the help of a machine called a cycler or continuous ambulatory and this process involves many of exchanges per day 
and it is causing infusion and drainage of the solution from the peritoneal cavity using the gravity only. Continuous ambulatory PD (CAPD) is now a preferred mode of the treatment in patients with end-stage renal disease [14]. CAPD does not require advanced technologies, much infrastructure, or need for dialysis staff support, it could be an ideal form of RRT in lowmiddle-income countries, particularly for those living in remote areas [15].

In acute and chronic renal failure treatment, the procedure of PD has a widespread of acceptance because of many reasons like, simplicity and it is more flexible and independence in addition to lack the need for regular intravascular access that limits daily performance. Furthermore, the preservation of the residual renal function is better and dietary restrictions are less when compared with other types of dialysis treatment such as hemodialysis (HD) [16], [17]. This resulted in use of $\mathrm{PD}$ for treatment of renal failure over the past four decades in many hospitals to reach $11 \%$ of all RRT [18].

Accordingly, the PD has many of advantages in comparison with HD; it gives the patients more freedom to do daily activities as well as easily use and speed, low cost, and absence for need of highly skilled operator and anticoagulation [19]. In addition, many of data suggest that the transplant outcomes in patients that used PD against HD are improved and myocardial stunning in PD is less, therefore, the PD may be considered as a modality of choice in patients with cardiovascular comorbidities [20], [21], [22]. In addition, quality of life is better in patients on $P D$ than HD [23]. In addition, in patients whom vascular access is challenging, $P D$ is considered as an alternative method of dialysis. PD also provides good control of diabetic complications in diabetic patients on RRT [24].

In spite of these advantages, but the PD has many of potential complications, infectious, and noninfectious. The infectious complications of PD include peritonitis that also known as a technique failure and this considered as the major complication of PD and primary cause that made patients to switch from $P D$ to $\mathrm{HD}$ as well as increase risk of morbidity and mortality in addition to increasing treatment cost and hospitalization, infection of the catheter exit site, tunnel infection also reported [25], [26], [27], [28].

While, the non-infectious complications include, dysfunction of catheter, catheter obstruction or poor drainage, edema or leakage of dialysate subcutaneously or as a peritoneal-pleural fistula, peritoneal herniation, intra-abdominal adhesions abdominal wall weakens, and sclerosing encapsulating peritonitis in addition to hydrothorax [19], [29], [30].

The aim of this study was to evaluate the complications of PD in patients with CKD.

\section{Methods}

\section{Study design and setting}

It is a cross-sectional study, involved 140 patients (74 as female and 66 as male), aged between 18 and 80 years old and suffered from CKD under MCAPD in the dialysis unit of the renal center. Patients who diagnosed with acute kidney disease and under PD or HD were excluded from this study.

\section{Data collection}

All CKD patients seeking for maintenance CAPD were observed during the study, many of information were taken regarding the underlying causes of CKD, type of operation, frequency of dialysis, and concomitant complications. Age, gender, and past medical history also taken. Additional information regarding any adverse events during dialysis session and the required management is provided by attending physicians as peer slandered protocol. All data regarding the sociodemographic profile of the patient, vitals, etiological diagnosis, frequency and duration of dialysis, and dialysis-related complications were taken in preformed forma after getting the informed consent from all patients.

Table 1: Baseline characteristics of patients undergoing continuous ambulatory peritoneal dialysis

\begin{tabular}{|c|c|c|}
\hline Baseline variables & No. & $\%$ \\
\hline \multicolumn{3}{|l|}{ Age (years) } \\
\hline $18-38$ & 46 & 32.8 \\
\hline $39-59$ & 49 & 35 \\
\hline $60-80$ & 45 & 32.2 \\
\hline \multicolumn{3}{|l|}{ Gender } \\
\hline Male & 66 & 47 \\
\hline Female & 74 & 53 \\
\hline \multicolumn{3}{|l|}{ Complication } \\
\hline Present & 48 & 34.2 \\
\hline Absent & 92 & 65.7 \\
\hline \multicolumn{3}{|l|}{ Type of operation } \\
\hline Open method & 12 & 8.5 \\
\hline Laparoscopy & 128 & 91.5 \\
\hline \multicolumn{3}{|c|}{ History of medical disease } \\
\hline Hypertension & 80 & 57.1 \\
\hline Diabetic & 18 & 12.8 \\
\hline Anemia & 78 & 55.7 \\
\hline Total & 140 & 100 \\
\hline
\end{tabular}

\section{Statistical analysis}

Statistical analysis was performed using SPSS version 18 (Statistical Package for the Social Science), using frequency, mean and standard deviation. When $p \leq 0.05$, it was considered statistically significant for described variables.

\section{Results}

From the total 140 patients, there were $74(53 \%)$ as females and $66(47 \%)$ as male. Table 1 shows the demographic and baseline characters of 
the patients with CKD under CAPD. Results of Table 2 indicated that there is a significant difference in the presence or absence of complications according to the gender $(p \leq 0.05)$. Table 3 showed that there is no significant difference in the presence or absence of complications according to the age $(p \geq 0.05)$.

Table 2: Distribution of presence and absence of complications according to the gender of study population

\begin{tabular}{lllll}
\hline Gender & Complications & & Total & p-value \\
\cline { 2 - 3 } & Present & Absent & & \\
\hline Male & 14 & 51 & 65 & 0.003 \\
Female & 34 & 41 & 75 & \\
Total & 48 & 92 & 140 & \\
\hline
\end{tabular}

The result of Table 4 showed that there is a significant difference in the values of hemoglobin, urea $(p \leq 0.05)$, and a highly significant difference in the level of creatinine $(p \leq 0.0001)$ before and after dialysis process. Figure 1 shows the distribution of complications according to the type of operation that used in CAPD either open method or laparoscopy.

Figure 2 showed the distribution of infection according to time of occurrence after CAPD either by open method or laparoscopy.

Table 3: Distribution of presence and absence of complications according to the age of study population

\begin{tabular}{lllll}
\hline Age (years) & Complications & & Total & p-value \\
\cline { 2 - 3 } & Present & Absent & & \\
\hline $18-38$ & 20 & 26 & 46 & 0.21 \\
$39-59$ & 16 & 33 & 49 & \\
$60-80$ & 12 & 33 & 45 & \\
Total & 48 & 92 & 140 & \\
\hline
\end{tabular}

\section{Discussion}

In the current study, there is a significant difference in the distribution of complications among gender and the female patients had a higher incidence of both infectious and non-infectious complications. This could attribute to that peritoneum attach with uterus that which open with vagina to urethra and those female more liable for UTI because of poor controlled the complete evacuation process of urinary bladder [31], where the complicated UTI has a higher risk of chronicity, recurrence, and/or progression and may be associated with severe disease progression [32], this explained by vaginal infections that serving as a potential reservoir for urinary tract infecting microorganism in female patients [33]. In addition, the normal female urinary tract has a comparatively short urethra, as a result carries an inherent predisposition to proximal seeding of bacteria [34].

Table 4: Values of hemoglobin, urea, and creatinine before and after peritoneal dialysis for the patients of the study

\begin{tabular}{|c|c|c|c|c|}
\hline & & Mean $\pm S D$ & Correlation & $\mathrm{p}$-value \\
\hline \multirow[t]{2}{*}{ Pair 1} & Pre-dialytic hemoglobin & $8.933 \pm 2.037$ & 0.191 & 0.024 \\
\hline & Post-dialytic hemoglobin & $9.283 \pm 1.520$ & & \\
\hline \multirow[t]{2}{*}{ Pair 2} & Pre-dialytic urea & $181.151 \pm 63.83$ & 0.208 & 0.014 \\
\hline & Post-dialytic urea & $134.501 \pm 61.712$ & & \\
\hline \multirow[t]{2}{*}{ Pair 3} & Pre-dialytic creatinine & $8.356 \pm 3.3389$ & 0.366 & 0.0001 \\
\hline & Post-dialytic creatinine & $6.634 \pm 2.826$ & & \\
\hline
\end{tabular}

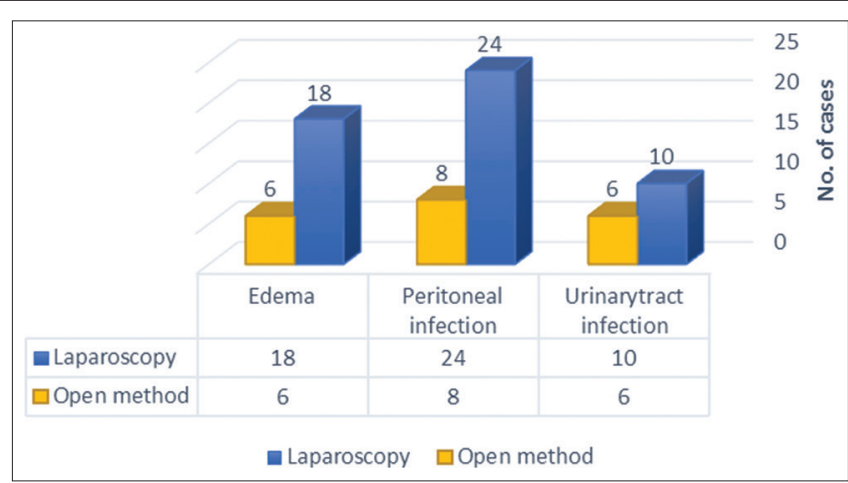

Figure 1: Distribution of complications according to the type of operation

Furthermore, the results showed that there is no significant difference in the distribution of complications among age, but the study showed that there is about two-third of the patients in the study who were more than 38 years and the median age is $46.69 \pm 16.6$ years, this can be explained by increasing the incidence of CKD and their underlying risk factors, especially diabetic mellitus and hypertension, also there is a growing evidence of age-related renal function decline as shown by Hill et al., 2016, who showed that the prevalence of CKD increased with age [35]. A study by Chou et al., 2019, also showed increasing in the incidence of ESRD in elderly patients with CKD [36].

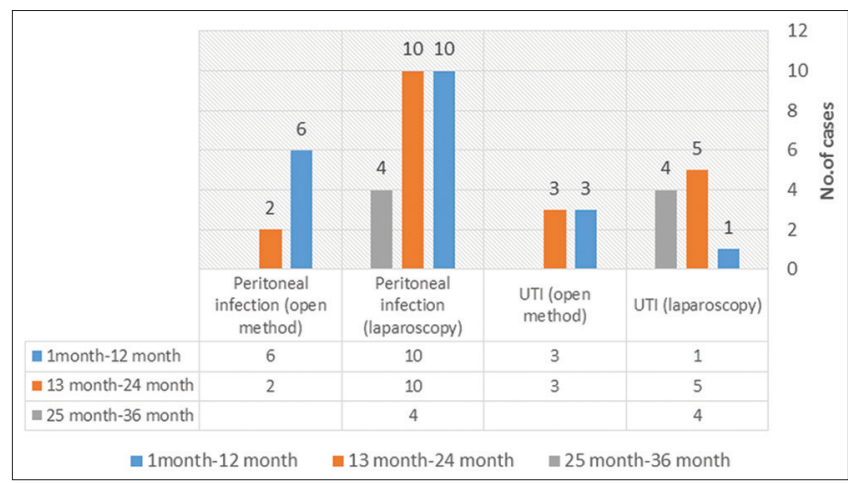

Figure 2: Distribution of infection according to time of occurrence

During the study period, there are 140 patients on MCAPD and the study reported that there is much lower rate of complications, especially peritonitis among patients on laparoscope operation in compared with the open operation, these results were comparable with Bircan and Kulah, 2015, study and Okpechi et al., 2020, study respectively [37], [38]. In addition, patients with open abdomen PD developed the complications earlier than those with laparoscope MCAPD.

The laparoscope process shown a minimal invasive, more acceptable, and higher safety profile in addition to better outcome and less incidence of catheter obstruction and change in comparison with the open operation, accordingly, there is a universal orientation toward laparoscope PD operations [39], [40]. This reflects the large number of patients with laparoscope PD in the current study and clinicians preference of laparoscopic over open CAPD in the current study. 
Furthermore, when compared with HD, this type of RRT is more preferred [41] and utilized treatment that affords medical and lifestyle benefits to the patient and financial savings to the health-care system [42]

In addition, when compared our results, we found that the frequency of complication is much lower than that of HD that documented in the previous studies. A study by Bartaula et al. reported that the complications were documented in $58.3 \%$ of the patients [43], while in this study, the complications occurred in about $34.2 \%$, this could be attributed to the. Another study by Mehrotra et al., 2016, also documented the results of several studies that proven the reduce the rate of complications with improved survival rate in ESRD patients on $\mathrm{PD}$ compared with $\mathrm{HD}$, these results were parallel with the current results [44].

Peritoneal infection or peritonitis is the most prevalent complication among the other complications in the current study. Comparable results were reported in several earlier clinical studies worldwide [45]. This complication could be associated with increase hospitalization, treatment cost, as well as raising the rate of mortality [25].

When compare the rate of peritonitis in the current study with the rates that documented by previous study by Okpechi et al. [38]. We noted that this study showed a lower rate of complications, this could be attributed to intensive and continuous training of medical staff who responsible for preforming of laparoscopes in addition to the continuous patients follow-up as well as the rational and specific selection of patients who legible to undergo maintenance CAPD to lowers as possible CAPD-related complications.

This study also showed that $55.7 \%$ of patients were anemic. Male patients showed a relatively higher level of hemoglobin, this result was relatively similar to previous results [46], [47] that showed the prevalence of anemia in CKD at different stages and differences in the levels of hemoglobin between male and female, respectively. This result is well predicted since anemia is one of the popular complications of CKD [48] and it increases the risk of CKD progression [49]. Anemia is more frequent in female and could be worsened by hemorrhagic effluent or hemorrhagic complications of dialysis.

Edema was also reported in both laparoscopic and open abdomen maintenance CAPD, especially genital edema but with less prevalence among laparoscopic PD. It is considered as one of the established noninfectious complications of PD. It is a common manifestation of dialysate leakage from the peritoneal cavity through a defect in the abdominal wall caused by hernias; peritoneal tears; leaks around the dialysis catheter; trauma; fluid overload; and malignancy [50]

Both blood urea and serum creatinine levels were significantly lowered after PD, this reflects the success of RRT that promotes preserving or even improvement of renal function among patients on dialysis.
Finally, hemoglobin level also had been improved after dialysis, despite this improvement not result in correction of anemia, but it is statistically significant. This might be related to the elimination of uremic toxins through PD.

\section{Conclusion}

Peritoneal infection or peritonitis is the most prevalent complication among the other complications in the current study. There is much lower rate of complications among patients on PD in compared with $\mathrm{HD}$ and on laparoscope operation in compared with the open operation.

\section{Statement of Ethics}

Patients have given their written informed consent and that the study protocol was approved by the institute's committee on human research.

\section{Authors' Contributions}

Evan Hameed: Study design, drafting the article, and data collection. Rawaa Shareef: Data collection, interpretation of the data, and analysis. Yasir Sharba and Zahraa Sharba: Contribute equally to this work. All authors read and approved the final manuscript.

\section{References}

1. Li PK, Chow KM, Van de Luijtgaarden MW, Johnson DW, Jager KJ, Mehrotra R, et al. Changes in the worldwide epidemiology of peritoneal dialysis. Nat Rev Nephrol. 2017;13(2):90-103. http://doi.org/10.1038/nrneph.2016.181 PMid:28029154

2. Chen TK, Sperati CJ, Thavarajah S, Grams ME. Reducing kidney function decline in patients with CKD: Core curriculum 2021. Am J Kidney Dis. 2021;77(6):969-83. http://doi.org/10.1053/j. ajkd.2020.12.022 PMid:33892998

3. Crews DC, Bello AK, Saadi G. 2019 world kidney day editorial burden, access, and disparities in kidney disease. J Bras Nefrol. 2019;41(1):1-9. http://doi. org/10.1590/2175-8239-JBN-2018-0224

PMid:31063178 
4. Yang C, Wang H, Zhao X, Matsushita K, Coresh J, Zhang L, et al. CKD in China: Evolving Spectrum and public health implications. Am J Kidney Dis. 2020;76(2):258-64. http://doi. org/10.1053/j.ajkd.2019.05.032

PMid:31492486

5. Lv JC, Zhang LX. Prevalence and disease burden of chronic kidney disease. Adv Exp Med Biol. 2019;1165:3-15. http://doi. org/10.1007/978-981-13-8871-2_1

PMid:31399958

6. $\quad \mathrm{Ng}$ JK, Li PK. Chronic kidney disease epidemic: How do we deal with it? Nephrology (Carlton). 2018;23(Suppl 4):116-20. http:// doi.org/10.1111/nep.13464

PMid:30298662

7. Provenzano M, Coppolino G, Faga T, Garofalo C, Serra R, Andreucci M. Epidemiology of cardiovascular risk in chronic kidney disease patients: The real silent killer. Rev Cardiovasc Med. 2019;20(4):209-20. http://doi.org/10.31083/j. rcm.2019.04.548

PMid:31912712

8. GBD Chronic Kidney Disease Collaboration. Global, regional, and national burden of chronic kidney disease, 1990-2017: A systematic analysis for the global burden of disease study 2017. Lancet. 2020;395(10225):709-33. http://doi.org/10.1016/ S0140-6736(20)30045-3

PMid:32061315

9. Kwek JL, Kee TYS. World kidney day 2020: Advances in preventive nephrology. Ann Acad Med Singap. 2020;49(4):175-9. PMid:32419005

10. Carney EF. The impact of chronic kidney disease on global health. Nat Rev Nephrol. 2020;16(5):251. http://doi.org/10.1038/ s41581-020-0268-7

PMid:32144399

11. Kadhim HM, Al-Ghanimi HH, Al-Dedah RM. Haematological Parameters and Biochemical Indices in Patients with Chronic Kidney Disease before Haemodialysis Al-Furat Al-awsat Governorates/lraq. Cite as: AIP Conference Proceedings 2290, 020004; 2020. https://doi.org/10.1063/5.0027856

12. Andreoli MC, Totoli C. Peritoneal dialysis. Rev Assoc Med Bras (1992). 2020;66 (Suppl 1):s37-44. https://doi.org/10.1590/18069282.66.S1.37

PMid:31939534

13. Choudhary G, Manapragada PP, Wallace E, Bhambhvani P. Utility of scintigraphy in assessment of noninfectious complications of peritoneal dialysis. J Nucl Med Technol. 2019;47(2):163-8. https://doi.org/10.2967/jnmt.118.223156 PMid:30700534

14. Pindi G, Kawle V, Sunkara RR, Darbha MS, Garikaparthi S. Continuous ambulatory peritoneal dialysis peritonitis: Microbiology and outcomes. Indian J Med Microbiol. 2020;38(1):72-77. https://doi.org/10.4103/ijmm.IJMM_20_251 PMid:32719212

15. Wearne N, Kilonzo K, Effa E, Davidson B, Nourse P, Ekrikpo U, et al. Continuous ambulatory peritoneal dialysis: Perspectives on patient selection in low to middle-income countries. Int J Nephrol Renovasc Dis. 2017;10:1-9. https://doi.org/10.2147/ IJNRD.S104208

PMid:28115864

16. Afshan S, Earl TM, Anderson CD, Dixit M. A rare complication of peritoneal dialysis (PD) catheter: Perforation of sigmoid colon by migrating tip of peritoneal dialysis catheter. Am J Case Rep. 2020;21:e922828. https://doi.org/10.12659/AJCR.922828 PMid:32669533

17. Tang SC, Lai KN. Peritoneal dialysis: The ideal bridge from conservative therapy to kidney transplant.
J Nephrol. 2020;33(6):1189-94. https://doi.org/10.1007/ s40620-020-00787-0.

PMid:32654095

18. Cho Y, Bello AK, Levin A, Lunney M, Osman MA, Ye F, et al. Peritoneal dialysis use and practice patterns: An international survey study. Am J Kidney Dis. 2021;77(3):315-25. https://doi. org/10.1053/j.ajkd.2020.05.032

\section{PMid:32800844}

19. Tan R, Sieunarine K. Peritoneal dialysis catheter intralumina fibrin cast: A complication after prolonged placement. Case series with a review of literature and the management of this complication. J Vasc Access. 2020;21(6):1029-33. https://doi. org/10.1177/1129729820917855

\section{PMid:32364814}

20. Barman TK, Roy S, Hossain SM, Salahuddin AZ, Huq MO. Comparison of cardiac outcome of continuous ambulatory peritoneal dialysis and hemodialysis in CKD5 patients with heart failure. Mymensingh Med J. 2020;29(4):793-9.

PMid:33116079

21. Chrysohoou C, Bougatsos G, Magkas N, Skoumas J, Kapota A, Kopelias $\mathrm{J}$, et al. Peritoneal dialysis as a therapeutic solution in elderly patients with cardiorenal syndrome and heart failure: A case-series report. Hellenic J Cardiol. 2020;61(2):73-7. https://doi.org/10.1016/j.hjc.2019.04.010 PMid:31055051

22. Bonomini M, Borras FE, Troya-Saborido M, Carreras-Planella L, Di Liberato L, Arduini A. Proteomic research in peritoneal dialysis. Int J Mol Sci. 2020;21(15):5489. https://doi.org/10.3390/ ijms21155489

PMid:32752018

23. Hsu CC, Huang CC, Chang YC, Chen JS, Tsai WC, Wang KY. A comparison of quality of life between patients treated with different dialysis modalities in Taiwan. PLoS One. 2020;15(1):e0227297. https://doi.org/10.1371/journal. pone. 0227297

PMid:31907493

24. Gorsane I, Ben Hamida S, Ben Hamida F, Ounissi M, Harzallah A, Ben Abdallah T. Peritoneal dialysis in diabetes patients. Tunis Med. 2019;97(8-9):1017-20.

PMid:32173851

25. Al Sahlawi M, Bargman JM, Perl J. Peritoneal dialysisassociated peritonitis: Suggestions for management and mistakes to avoid. Kidney Med. 2020;2(4):467-75. https://doi. org/10.1016/j.xkme.2020.04.010

PMid:32775987

26. Kokubu M, Matsui M, Uemura T, Morimoto K, Eriguchi M, Samejima K, et al. Relationship between initial peritoneal dialysis modality and risk of peritonitis. Sci Rep. 2020;10(1):18763. https://doi.org/10.1038/s41598-020-75918-5

PMid:33127929

27. Morrisette T, Canada RB, Padgett D, Hudson JQ. Factors associated with increased hospital length of stay in peritoneal dialysis patients with peritonitis: A need for antimicrobial stewardship? Hosp Pharm. 2020;55(1):50-7. https://doi. org/10.1177/0018578718817944 PMid:31983767

28. Bieber S, Mehrotra R. Peritoneal dialysis access associated infections. Adv Chronic Kidney Dis. 2019;26(1):23-9. https://doi. org/10.1053/j.ackd.2018.09.002

PMid: 30876613

29. Cheng BC, Tsai NW, Lai YR, Huang CC, Lu CH. Impact of intraabdominal adhesion on dialysis outcome in peritoneal dialysis patients. Biomed Res Int. 2018;2018:1978765. https://doi. org/10.1155/2018/1978765 


\section{PMid:30356377}

30. Al-LawatiAl, Al Shaibi M, Al Mahruqi G, Augustine T, Moinuddin Z, Al Hinai $M$, et al. Encapsulating peritoneal sclerosis: A case report and literature review. Am J Case Rep. 2020;21:e925341. https://doi.org/10.12659/AJCR.925341

PMid:33011732

31. Geerlings SE. Clinical presentations and epidemiology of urinary tract infections. Microbiol Spectr. 2016;4(5):2. https:// doi.org/10.1128/microbiolspec.UTI-0002-2012

PMid:27780014

32. Kranz J, Wagenlehner FM, Schneidewind L. Komplizierte Harnwegsinfektionen (Complicated urinary tract infections). Urologe A. 2020;59(12):1480-5. https://doi.org/10.1007/ s00120-020-01343-1

PMid:33025113

33. Stapleton AE. The vaginal microbiota and urinary tract infection. Microbiol Spectr. 2016;4(6):25. https://doi.org/10.1128/ microbiolspec.UTI-0025-2016 PMid:28087949

34. Sabih A, Leslie SW. Complicated Urinary Tract Infections. Treasure Island, FL: StatPearls Publishing; 2021. PMid:28613784

35. Hill NR, Fatoba ST, Oke JL, Hirst JA, O'Callaghan CA, Lasserson DS, et al. Global prevalence of chronic kidney disease a systematic review and meta-analysis. PLoS One. 2016;11(7):e0158765. https://doi.org/10.1371/journal. pone.0158765

PMid:27383068

36. Chou YH, Yen CJ, Lai TS, Chen YM. Old age is a positive modifier of renal outcome in Taiwanese patients with stages 3-5 chronic kidney disease. Aging Clin Exp Res. 2019;31(11):1651-9. https://doi.org/10.1007/s40520-018-01117-y PMid:30628047

37. Bircan HY, Kulah E. Effects of a novel peritoneal dialysis: The open versus laparoscopic preperitoneal tunneling technique. Ther Apher Dial. 2016;20(1):66-72. https://doi. org/10.1111/1744-9987.12377

PMid:26638124

38. Okpechi IG, Ekrikpo U, Moloi MW, Noubiap JJ, OkpechiSamuel US, Bello AK. Prevalence of peritonitis and mortality in patients with ESKD treated with chronic peritoneal dialysis in Africa: A systematic review. BMJ Open. 2020;10(12):e039970. https://doi.org/10.1136/bmjopen-2020-039970 PMid:33361076

39. Janez J. Laparoscopically assisted insertion of peritoneal dialysis catheter. J Minim Access Surg. 2019;15(1):80-3. https:// doi.org/10.4103/jmas.JMAS_196_17 PMid:29319017

40. Carpenter JL, Fallon SC, Swartz SJ, Minifee PK, Cass DL, Nuchtern JG, et al. Outcomes after peritoneal dialysis catheter placement. J Pediatr Surg. 2016;51(5):730-3. https://doi. org/10.1016/j.jpedsurg.2016.02.011

PMid:26936290

41. Dias DB, Mendes ML, Caramori JT, Dos Reis PF, Ponce D. Urgent-start dialysis: Comparison of complications and outcomes between peritoneal dialysis and haemodialysis. Perit Dial Int. 2021;41(2):244-52. https://doi. org/10.1177/0896860820915021

PMid:32223522

42. Smith BM, Dan AG. Operative technique for laparoscopic placement of continuous ambulatory peritoneal dialysis catheter J Laparoendosc Adv Surg Tech A. 2020;30(7):815-9. https://doi. org/10.1089/lap.2019.0750

PMid:32074477

43. Bartaula B, Subedi M, Kumar MM, Shrestha M, Bichha N Mudbhari B. Spectrum of complications in chronic kidney disease patients undergoing maintenance hemodialysis: An experience of a tertiary care center in Nepal. Saudi J Kidney Dis Transpl. 2019;30(1):208-14

PMid:30804283

44. Mehrotra R, Devuyst O, Davies SJ, Johnson DW. The current state of peritoneal dialysis. J Am Soc Nephrol. 2016;27(11):3238-52. https://doi.org/10.1681/ASN.2016010112 PMid:27339663

45. Szeto CC, Li PK. Peritoneal dialysis-associated peritonitis. Clin J Am Soc Nephrol. 2019;14(7):1100-5. https://doi.org/10.2215/ CJN.14631218 PMid:31068338

46. Stauffer ME, Fan T. Prevalence of anemia in chronickidney disease in the United States. PLoS One. 2014;9(1):e84943. https://doi.org/10.1371/journal.pone.0084943 PMid:24392162

47. Sofue $T$, Nakagawa $N$, Kanda $E$, Nagasu $H$, Matsushita $K$, Nangaku $\mathrm{M}$, et al. Prevalence of anemia in patients with chronic kidney disease in Japan: A nationwide, cross-sectional cohort study using data from the Japan chronic kidney disease database (J-CKD-DB). PLoS One. 2020;15(7):e0236132. https://doi.org/10.1371/journal.pone.0236132 PMid:32687544

48. Shaikh $\mathrm{H}$, Aeddula NR. Anemia of Chronic Renal Disease Treasure Island, FL: StatPearls Publishing; 2021. PMid:30969693

49. Hanna RM, Streja E, Kalantar-Zadeh K. Burden of anemia in chronic kidney disease: Beyond erythropoietin. Adv Ther. 2021;38(1):52-75. https://doi.org/10.1007/s12325-020-01524-6 PMid:33123967

50. Jorge J, Haggerty SP. Acute genital edema during peritoneal dialysis: A review for surgeons. Am Surg. 2015;81(11):1187-94. PMid:26672592 